


\section{Perspectivas lusófonas na academia e na mídia: entrevista com Isabel Ferin}

\author{
Lusophone perspectives in academy \\ and media: interview with Isabel Ferin
}

\section{Aline Bianchini' $[$ G, Ciro Götz}

\section{ENTREVISTA}

Isabel Ferin é licenciada em História pela Faculdade de Letras de Lisboa, mestre e doutora em Ciências da Comunicação pela Universidade de São Paulo (USP), Brasil, e pós-doutora pelo Centre National de la Recherche Scientifique (CNRS), em Paris. Atualmente, está vinculada à Universidade de Coimbra, em Portugal, dedicando-se aos estudos de análise da imprensa e dos media, com foco principal na televisão.

Durante o Seminário Cooperação e Internacionalização em Comunicação, que comemorou, em setembro de 2014, os 20 anos do Programa de Pós-Graduação em Comunicação Social (PPGCOM) da PUCRS, Isabel Ferin falou sobre a importância da reflexão acadêmica abarcar a perspectiva lusófona e aproximar-se deste espaço, que não é demarcado apenas pelo idioma. Segundo Ferin, trata-se de "um estado mental partilhado por muitos objetos que se ocupam das questões culturais: está ligado à diáspora, à herança política e à história". Esse e outros temas foram abordados durante a conferência Comunicação, Tecnologia, Identidade e Sociedade e ao longo de entrevista concedida à Sessões do Imaginário.

Sessões do Imaginário - A senhora afirma que, hoje, nossos objetos de pesquisa estão sendo moldados à realidade de um mundo globalizado, distante da nossa realidade dentro do espaço lusófono. Em sua opinião, que objetos deveriam estar recebendo mais atenção no meio acadêmico?

Isabel Ferin - Eu penso que pertencem mesmo a uma questão política e àquilo que nos une. Nós temos uma cultura e uma história comum que têm alguns séculos e, a partir daí, algumas concessões políticas foram moldadas, que se replicam e contextualizam em novos tempos e espaços. E é importante trabalharmos essa questão dentro do acontecimento da nossa história e não com o aporte teórico e 


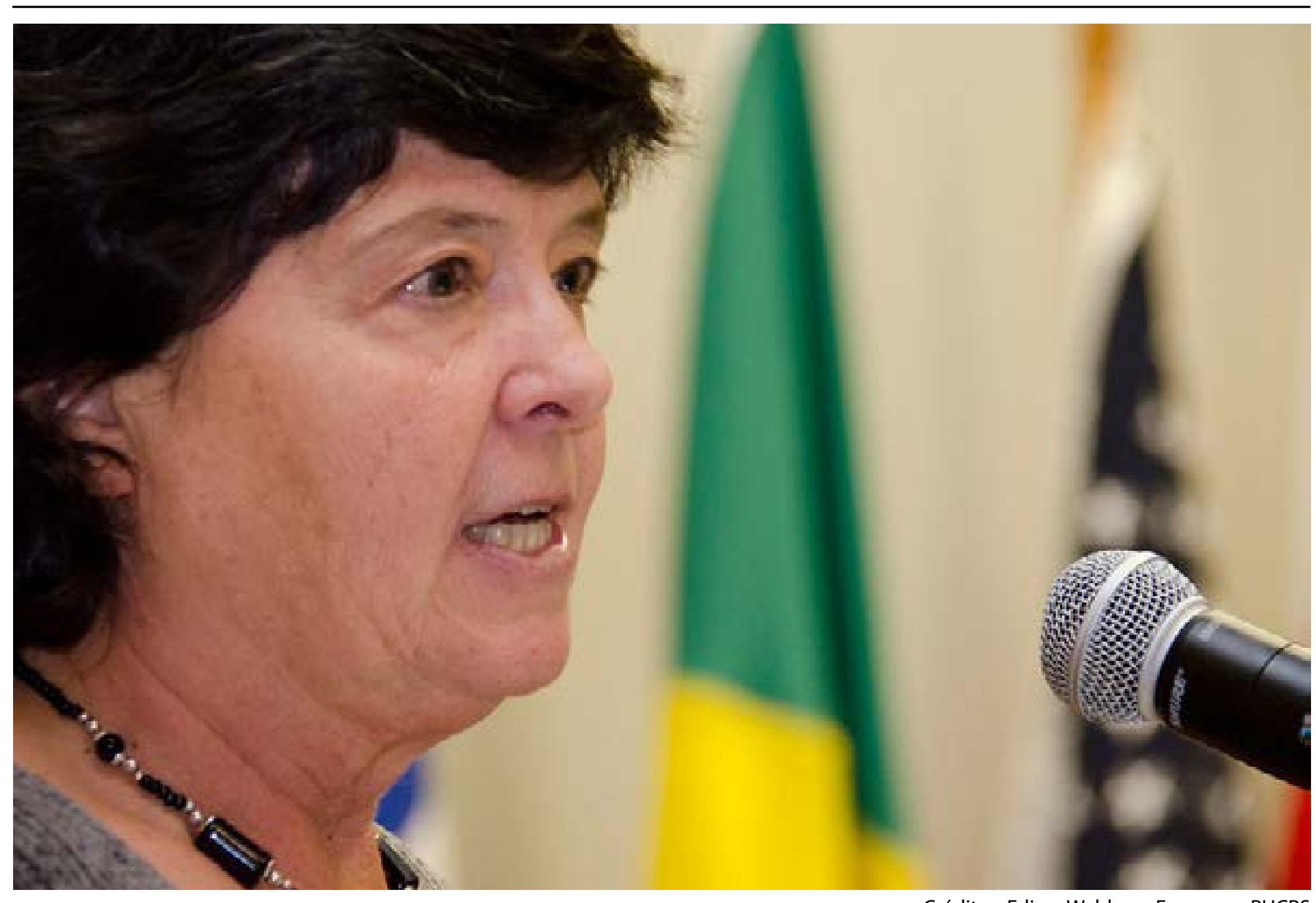

Créditos: Edissa Waldow - Famecos - PUCRS contextual anglo-saxônico, independentemente de eles terem um aparato teórico que nos interessa e que temos que conhecer. Outra questão, eu penso, e que é importante, são os fluxos econômicos entre os países. Não falo lusófonos, mas no espaço lusófono, que é diferente, relativamente à mídia. Portanto, consumos midiáticos, hoje, pela internet, são feitos por pessoas que têm aproximação a esse espaço lusófono. Estou falando de música, ficção, teatro e conteúdo de uma maneira geral.

SI - Ainda em relação à academia, como podemos, nesse espaço lusófono, articular trocas de informações e estreitar laços?

IF - Eu vejo isso através desses encontros, a ida de pesquisadores portugueses para o Brasil e do Brasil para Portugal e a criação de redes de trabalho em temáticas. Os financiamentos são difíceis, mas, por vezes, encontram-se nessa área. E penso que temos tudo a ganhar ao estreitar essas redes, sobretudo com os mais jovens que têm um futuro pela frente.

SI - Quando a senhora fala sobre a questão colonizador-colonizado, está se referindo apenas à relação Brasil e Portugal ou também entre outros países? A senhora se refere apenas à cultura?

IF - Sobre a relação colonizador-colonizado, parto do princípio de império, portanto, tivemos um império. Todos nós participamos nesse império, partilhamos um império, uns na posição de colonizadores e outros na posição de colonizados. Isso marca, definitivamente, a relação entre os povos. Mas, simultaneamente, essas relações vão se alterando e, por outro lado, o colonizador, neste caso Portugal, o império português, 
também foi colonizado em diferentes situações e momentos por outros impérios. Portanto, essa relação transmite-se, ou seja, o império português, em determinado momento, foi vassalo do império inglês e depois essa vassalagem se replica no Brasil, na Índia portuguesa, etc. Essas relações devem ser trabalhadas nesse sentido e não apenas na ideia do colonizador todo poderoso, único, porque o nosso espaço lusófono tem essas particularidades, e essas particularidades tornam mesmo as relações diferentes.

SI - A grande inserção de produtos midiáticos do Brasil em outros países também altera essa relação? Seria um outro tipo de colonização?

IF - Isso tem diferenças relativamente com outros pensadores portugueses, nomeadamente mais tradicionais que consideram que o Brasil é, atualmente, o grande colonizador cultural desse espaço. Eu não considero que seja o colonizador. Acho que o Brasil, na verdade, sem ter uma política definida, consegue manter o espaço unido através dessa veiculação de conteúdos e, futuramente, isso será um benefício para todos. Portanto, não vai como colonização, mas com capacidade de manter união com elementos novos, digamos, que são diáticos, mas que mantém os laços entre os diferentes territórios que constituem esse espaço lusófono.

SI - A senhora falou sobre a influência das novelas brasileiras, inclusive citou o exemplo de Angola, que faz novelas à moda brasileira. No caso dessas novelas de Angola, que mostram uma realidade brasileira protagonizada por atores angolanos, como isso se relaciona com a realidade daquele país? Qual sua função social?

IF - Eu penso que as novelas angolanas têm um papel politicamente simbólico de criar uma apetência dos angolanos de um imaginário ocidentalizado, mas brasileiro. Angola está emergindo como uma grande potência regional. Ela é uma potência regional africana, mas, simultaneamente, está se mostrando como apetência regional de relação com o ocidente, no Atlântico. E, nesse aspecto, o grande papel dessa telenovela - que, por acaso, é financiada pelo filho do presidente da república - tem esse objetivo. Mantém determinadas tradições, mas, simultaneamente, apresenta uma simbologia híbrida entre o ocidente, a América Latina e a África, ocidentalizada.

\section{Notas}

1. Doutoranda do Programa de Pós-Graduação em Comunicação Social da Pontifícia Universidade Católica do Rio Grande do Sul (PPGCOM/PUCRS Av. Ipiranga, 6681 - Prédio 7, Sala 319, CEP: 90619900, Porto Alegre - RS, Brasil). Bolsista CAPES. E-mail: li.bianchini@gmail.com

2. Mestrando do Programa de Pós-Graduação em Comunicação Social da Pontifícia Universidade Católica do Rio Grande do Sul (PPGCOM/PUCRS - Av. Ipiranga, 6681 - Prédio 7, Sala 319, CEP: 90619-900, Porto Alegre - RS, Brasil). Bolsista FAPERGS. E-mail: cirogotz@gmail.com

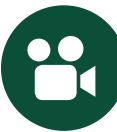
$\overline{\text { ASSISTA AO VÍDEO }}$

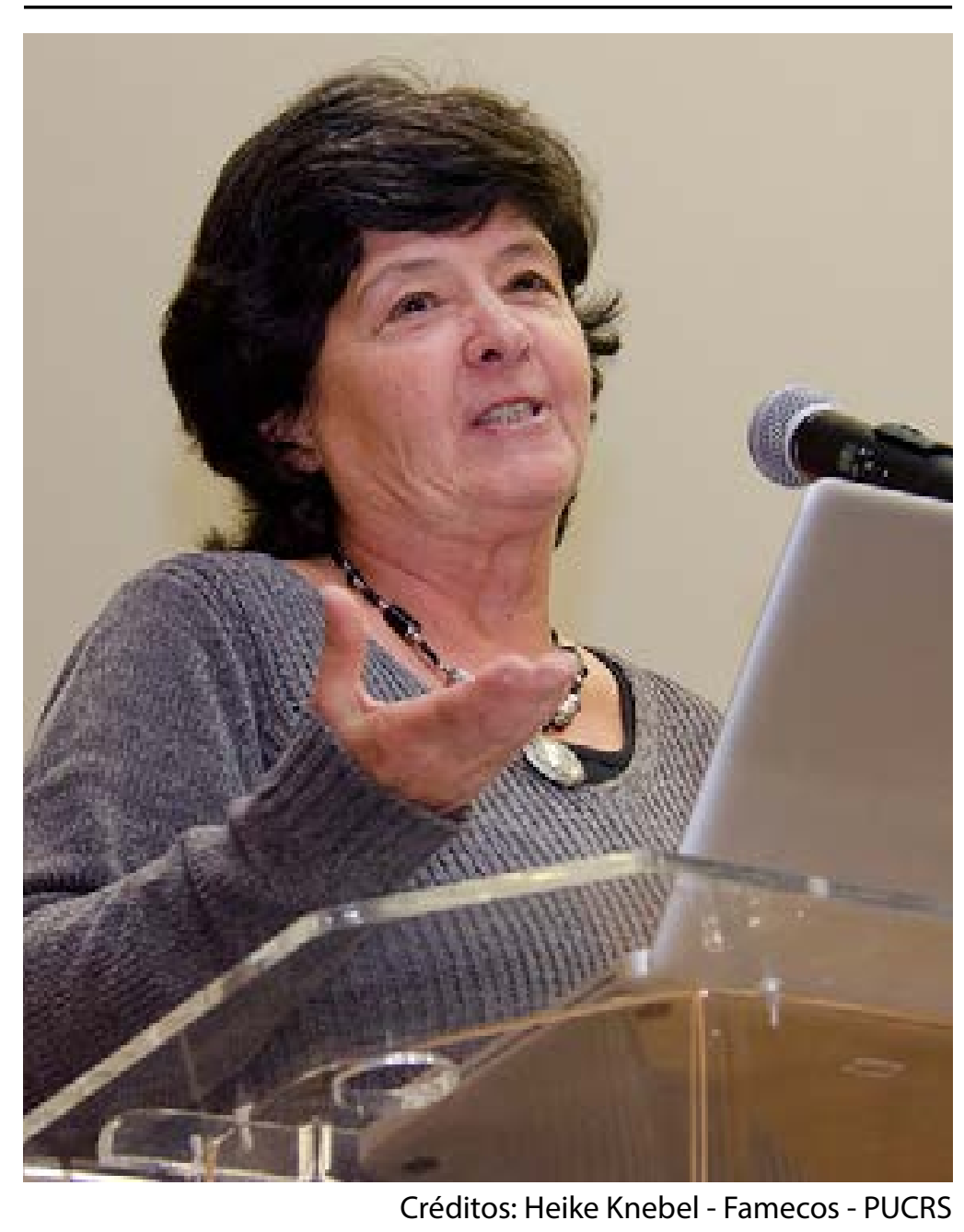

